\title{
As atividades no Método Terapia Ocupacional Dinâmica
}

\author{
Jô Benetton ${ }^{\mathrm{a}}$, Taís Quevedo Marcolino ${ }^{\mathrm{b}}$ \\ aDoutora em Saúde Mental. Pós-doutorado em História Social da Saúde. Professora do Curso de \\ Especialização no Método Terapia Ocupacional Dinâmica e diretora do Centro de Especialidades em \\ Terapia Ocupacional - CETO, São Paulo, SP, Brasil \\ ${ }^{b}$ Doutora em Educação. Professora adjunta do Departamento de Terapia Ocupacional da Universidade Federal de \\ São Carlos - UFSCar, São Carlos, SP, Brasil
}

\begin{abstract}
Resumo: Aborda-se a conceituação e utilização do instrumento atividades em terapia ocupacional nas proposições do Método Terapia Ocupacional Dinâmica (MTOD). Inicialmente, são apresentados aspectos gerais relacionados às atividades no MTOD, como a opção pelo nome "atividades", sua definição conceitual, sua utilização como instrumento e sua participação ativa na dinâmica da relação triádica. Na sequência, aborda-se o caráter das atividades - terapêutico, educativo e social, qualidades peculiares que demarcam essa terapia ocupacional. Além disso, explicita-se o uso das atividades como instrumento, tanto como elemento central nos processos que devem sustentar o raciocínio clínico (observação, informação, associação, estabelecimento de espaço de historicidade e construção de narrativa), como nos procedimentos de diagnóstico, no decorrer da clínica e na avaliação do processo. Por fim, apresenta-se nossa compreensão sobre o que são recursos no MTOD e sobre sua ligação intrínseca com a possibilidade de realização de atividades. Na construção do MTOD, a terapia ocupacional, enquanto prática de cuidado centrada na singularidade dos casos, foi posta como objeto de estudo, de modo a percorrer um caminho de construção de conhecimento. O esquema conceitual e instrumental apresentado neste trabalho decorreu desse esforço. Esperamos que esta apresentação possa ser útil para a formação inicial e continuada em Terapia Ocupacional, bem como para enriquecer o debate sobre o uso de atividades na profissão.
\end{abstract}

Palavras-chave: Terapia Ocupacional, Atividade, Métodos.

\section{Activities in the Dynamic Occupational Therapy Method}

\begin{abstract}
This paper addresses the concept and use of the instrument named 'activities' in occupational therapy, sustained by the propositions of the Dynamic Occupational Therapy Method (DOTM). Initially, we present general aspects related to the activities in the DOTM such as the option for the name 'activities', its conceptual definition, use as a tool, and active participation in the dynamic of triadic relationship. Further, it approaches the character of activities: therapeutic, educational and social qualities, which distinguish this peculiar occupational therapy. Moreover, the paper highlights the use of activities as a tool, both as a central element of the processes that should underpin clinical reasoning (observation, information, association, setting up space of historicity, and construction of narrative), and as an element belonging to diagnostic procedures, to the course of clinical process, and to evaluation. Finally, we present our understanding of what we call resources in DOTM, and its intrinsic connection with the possibility of performing 'activities'. For the creation of DOTM, occupational therapy, as a practice focused on the uniqueness of the case, was made the object of study in order to promote knowledge construction. The conceptual and instrumental framework presented in this work held this effort. We hope that this study could be useful for initial and continuing training in Occupational Therapy as well as for enriching the debate on the use of 'activities' in our profession.
\end{abstract}

Keywords: Occupational Therapy, Activity, Methods.

Autor para correspondência: Taís Quevedo Marcolino, Universidade Federal de São Carlos - UFSCar, Rod. Washington Luís, Km 235, Monjolinho, CEP 13565-905, São Carlos, SP, Brasil, e-mail: taisquevedo@gmail.com

Recebido em 15/7/2013; $1^{\text {a }}$ Revisão em 2/9/2013; Aceito em 4/10/2013. 


\section{Introdução}

Um método se define pelo seu desenho. Desenho esse que projeta os conceitos que o regem. Esses, por sua vez, em diferentes ordenações, devem potencializar uma rota particular para cada empreendedor. Lembramos que método é definido como "[...] ordem que se segue na investigação da verdade, no estudo de uma ciência ou para alcançar determinado fim [...]" (CUNHA, 1986, p. 517).

Assim sendo, um método, desenhado num caminho particular para terapeutas ocupacionais, é regido pela singularidade do seu emprego em diferentes situaçóes profissionais. $\mathrm{E}$ isso tanto se levarmos em consideração as situaçốes de assistência, como as de ensino e de pesquisa.

Um método tem de estar baseado em um projeto maior, que pode ser da ordem da prática ou da teoria. Partindo do estudo de atividades realizado por Marcolino e Fantinatti (2013), iremos tratar diretamente do Método Terapia Ocupacional Dinâmica (MTOD), desenvolvido no $\mathrm{CETO}^{1}$, principalmente em referência às produçóes dos últimos 10 anos.

O MTOD fundamenta-se no Paradigma da Terapia Ocupacional ${ }^{2}$. Fundada entre 1905 e 1915, dependendo das leis de ensino e das profissóes de cada estado norte-americano, a Terapia Ocupacional teve, como construtores, um único grupo de profissionais, composto por médicos, enfermeiras e assistentes sociais, liderados por Eleanor Clarke Slagle (BENETTON, 1998). Esse grupo deu início ao treinamento de auxiliares de enfermagem para desenvolver atividades em asilos, com o propósito de ampliar e modificar os hábitos dos pacientes, doentes mentais, na época, também chamados de deficientes mentais (SLAGLE, 2003).

As proposiçôes de Eleanor Clarke Slagle sobre o programa que denominou Treinamento de Hábitos desencadearam tanto a fundação de escolas, como da profissão nos Estados Unidos.
Esse programa estava baseado num projeto que procurava objetivar:

- Hábitos: sobrepor alguns, mudar outros e construir novos;

- Saúde: restauração e manutenção;

- Atividades: com a proposta de reeducação através da atividade;

- Reinserção social: como objetivo final.

O processo era chamado de Reeducação pela Ocupação, no qual moças de "boa família" eram treinadas nas atividades e na manutenção de hábitos saudáveis da mesma maneira que os doentes mentais.

No final da década de 1970, Kielhofner e Burke (1977) nomearam esse programa de práticas como construtor do Paradigma da Terapia Ocupacional. Atualmente, reforçamos essa ideia, ao levar em consideração a proposiçáo de Kuhn:

Suas realizaçōes foram suficientemente sem precedentes para atrair um grupo duradouro de partidários, afastando-os de outras formas de atividades científicas dissimilares. Simultaneamente, suas realizaçóes eram suficientemente abertas para deixar toda a espécie de problemas para serem resolvidos pelo grupo redefinido de praticantes da ciência (KUHN, 2003, p. 30).

Essas realizaçóes, como coloca Kuhn (2003), são da ordem da prática e definem problemas e métodos de um campo de investigaçáo. Desse modo, o MTOD vem sendo construído ao longo dos últimos 30 anos mantendo essa coerência paradigmática e se afastando de outras proposiçóes práticas centradas no paradigma da reabilitaçáo e no médico (BENETTON, 2005).

No Quadro 1 mostramos como mantemos os fundamentos do MTOD calcados no paradigma da Terapia Ocupacional.

A construção do MTOD é fundamentada na observação e investigação da clínica, em um processo de teoria da técnica (BENETTON, 1994). A teoria

Quadro 1. Fundamentos do MTOD calcados no paradigma da Terapia Ocupacional.

\begin{tabular}{|l|l|}
\hline \multicolumn{1}{|c|}{ Treinamento de hábitos } & \multicolumn{1}{c|}{ MTOD } \\
\hline Mudança de hábitos & Ampliação e eventual construção de cotidiano \\
\hline Sujeito-alvo/doentes & Sujeito-alvo com necessidades e/ou desejantes \\
\hline Saúde & Saúde \\
\hline Atividades & Atividades \\
\hline Reinserção social & Inserção social \\
\hline Treino e personalidade da terapeuta & Formação da terapeuta \\
\hline Reeducação & Educação \\
\hline
\end{tabular}


da técnica consiste no processo de, a partir da observação e análise dos fenômenos clínicos, construir generalizaçóes que possam oferecer explicaçóes de ordem teórica e que sustentem um arcabouço teórico-metodológico que se volte novamente para a clínica.

Nessa proposta, o núcleo central é a relação triádica, constituída por paciente, terapeuta ocupacional e atividades, que se caracteriza por possibilitar e manter uma dinâmica particular de funcionamento, na qual movimentos de ação e reação são determinantes da dinâmica relacional entre os três termos que a constituem.

Apesar de considerarmos que esses três termos deveriam ser apresentados e estudados como um conjunto, faremos um exercício (arriscado) de separá-los neste artigo.

\section{As atividades}

A escolha do termo atividades no MTOD está diretamente ligada ao uso da palavra na Terapia Ocupacional no Brasil (LIMA; PASTORE; OKUMA, 2011), ao afastamento da palavra ocupação, por sua forte associação a trabalho e ociosidade (BENETTON, 2008) e à própria definição da profissão dada pela World Federation of Occupational Therapy (WFOT):

Terapia Ocupacional é uma profissão da saúde centrada no cliente, preocupada com a promoção da saúde e bem-estar através da ocupação. O primeiro objetivo da terapia ocupacional é possibilitar às pessoas a participação nas atividades do dia a dia. Terapeutas ocupacionais atingem esse objetivo ao trabalhar com pessoas e comunidades para melhorar suas habilidades de engajarem-se em ocupaçóes que desejem, precisem ou são esperadas, ou modificando a ocupação ou o ambiente para melhor sustentar o engajamento ocupacional (WORLD..., 2012, tradução nossa).

Mesmo essa definição estando voltada para a participação em ocupaçóes, as atividades do cotidiano se mantêm presentes e é com elas que encontramos nosso lugar. No CETO, definimos a profissão a partir dela:

[...] a arte de aplicar conhecimentos científicos, empíricos e certas habilidades específicas decorrentes do uso de atividades à criação de estruturas, dispositivos e processos que são utilizados para converter recursos físicos, psicológicos e sociais em formas adequadas à prevenção, manutenção e tratamento em Saúde,
Educação, na área Social e demais correlatas (BENETTON, 1994, p.i, grifo nosso).

Desse modo, as atividades no MTOD, são definidas como o instrumento da terapia ocupacional e conceituadas como o terceiro termo da relação triádica (BENETTON, 1994).

Entendemos por definição o "espaço que um termo ocupa pela função ou pela relação existente" (LE PETIT ROBERT, 1993, p. 565, tradução nossa) e por conceito "a representaçáo mental genérica e abstrata de um objeto" (LE PETIT ROBERT, 1993, p. 429). Desse modo, conceitualmente, as atividades encontram-se indissociavelmente ligadas aos outros termos da relação triádica, criando uma estrutura mental que as coloca em "relação a". Enquanto que, ao defini-las como instrumento, possibilita-se a flexibilidade e a multiplicidade de maneiras com que podem ser clinicamente manejadas. Observe-se que sempre usamos atividades no plural e isso porque uma atividade sempre implica em muitas atividades, desde as mais subjetivas às mais concretas.

Sobre a possibilidade da participação das atividades em uma relação, provocando nela movimentos dinâmicos, além da observaçáo clínica, alvo do processo de teoria da técnica para a construção do MTOD, também buscamos apoio nas proposiçôes de Latour (2001) e Wagner (2010). Esses autores filoantropólogos estudam a relação dos objetos utilizados pelo homem dinamicamente, como uma extensão de seu próprio corpo, na afirmativa de uma relaçáo do sujeito com os objetos, o que particularizamos, no caso da terapia ocupacional, com suas atividades.

Ainda nessa direção, Nicolelis (2011), ao tratar das transformaçōes morfológicas e fisiológicas ocorridas no cérebro dos primeiros hominídeos e que levaram ao surgimento de novos processos mentais e de comportamentos perceptuais, motores e cognitivos, destaca a capacidade de produzir e compreender linguagem oral e outras duas adaptações, igualmente decisivas na construção da história da humanidade:

A primeira dessas adaptaçôes conferiu à nossa espécie e a seus ancestrais a capacidade de transformarem-se nos grandes artesões do planeta Terra. [...] A habilidade mental requerida para a confecção de ferramentas se destaca como um dos enredos revolucionários de maior impacto na história humana. Curiosamente, a segunda, e talvez ainda mais revolucionária adaptação comportamental e que emergiu da expansão do circuito frontoparietal 
[...] o mais requintado artífice gerado pelo processo evolutivo, o homem também adquiriu a capacidade de assimilar, ou incorporar, as ferramentas por ele produzidas como uma verdadeira extensão da simulação do modelo requintado do corpo criado por seu próprio cérebro (NICOLELIS, 2011, p. 320).

Esses apontamentos, que dáo valor à importância da relaçáo do ser humano com o que produz e com os objetos que utiliza como própria extensão de seu corpo para produzir, colaboram com um modo de pensar de que fazer atividades não gera somente produtos, em um sentido unidirecional, do ser humano para sua produção, mas sim também forçam uma relação com ele e uma relação da ordem de ter que produzir.

É dessa forma que compreendemos o movimento dinâmico da relação triádica, pois os três termos contribuem para a relação e as atividades, neste sentido, também podem ocupar um papel ativo na provocação de transformaçóes e do surgimento do novo.

Dessa forma, o conceito de atividades que norteia o MTOD, nas palavras atuais de Jô Benetton, é o de que as atividades, como instrumento da terapia ocupacional, são o terceiro termo de uma relação que acontece quando existe uma terapeuta ocupacional ${ }^{3}$ e um sujeito que ali se encontra por necessidade e/ ou desejo.

\section{O caráter das atividades no MTOD}

O caráter universal das atividades no MTOD é particularizado por um tratamento próprio e específico que nos permite distingui-las de outras formas de uso ou qualificação. Para nós, esse caráter é constituído pelo seu triplo domínio de funções: terapêutico, educativo e social.

Uma vez que o objetivo final da terapia ocupacional é a inserção social, isso determina definitivamente o seu caráter social, mesmo quando ela é realizada em uma sala de atendimento ou em uma instituição.

O caráter social das atividades no MTOD sustenta-se na construçáo e recuperação da dignidade da experiência e da ação cotidiana (BENETTON; TEDESCO; FERRARI, 2003). São as atividades que instrumentalizam a criação de espaços de saúde para construçôes na vida cotidiana.

Como podemos observar, tratar das atividades com seu caráter social implica em dois conceitos: o de espaços saudáveis e o de cotidiano. Aliás, dois aspectos impossíveis de serem separados.

Uma vez que a própria vida cotidiana está imbricada no social, como construção pessoal na prática social (BENETTON; TEDESCO; FERRARI, 2003), a terapia ocupacional no MTOD propóe-se a ser um espaço de encontro-construção para provocar transformaçóes.

Nesse sentido, os aspectos terapêutico e educacional se encontram conjugados como funçáo terapêutica e ação educativa que, através do aprender, do ensinar e de realizar atividades, se estende da clínica para a ampliação de atividades no cotidiano, pela ampliação de espaços saudáveis -

[...] com atividades podemos tratar, educar, alterar o ambiente e incluir pessoas num sistema que [lhes] permita integraçóes e interaçôes [...] (BENETTON, 2008, p. 29).

É esse tríplice vértice, contido no caráter das atividades, que dá ao nosso método uma sustentação segura, direcionando nossa assistência, ensino e pesquisa.

\section{$4 \mathrm{O}$ uso das atividades}

As atividades, enquanto instrumento, têm diversos objetivos, dentre eles: a observação, a informação, a análise, a educação, o tratamento, a composição de histórias e a inserçâo social. Para isso, as atividades são vindas e significadas na relação triádica. E a relação, por sua vez, é sustentada no e pelo fazer atividades (MORAES, 2008, p. 31).

Com essa afirmativa, Moraes (2008) introduz o proceder da terapeuta ocupacional, e o caminho para o seu agir é dado pelas atividades. Ao conectá-las ao proceder da terapeuta ocupacional, em todas as circunstâncias e em todos os tempos de um atendimento em terapia ocupacional, as atividades tornam-se centrais para os processos que sustentam o raciocínio clínico (MARCOLINO, 2012) da terapeuta ocupacional, e serão da ordem da:

Observaçáo, para o qual educar-se para observar é o desencadeante de todo um proceder prospectivo para uma terapia ocupacional.

Informação, para reterem-se observações e, sendo elas informaçôes para o proceder da terapeuta ocupacional, há que se educar a memória associativa.

Associaçáo, depois de observados e retidos em memórias, os acontecimentos podem e devem ser associados, uma vez que, diferentemente da 
linguagem verbal que favorece rapidamente as associações, no fazer atividades pode parecer não existir um encadeamento de ideias ou realizaçóes.

Estabelecimento de um Espaço de Historicidade, na medida em que uma terapeuta ocupacional observa, coleta informaçóes e fica atenta a possíveis associaçóes, ela está funcionando dentro de um sistema que estabelece um espaço que tanto permite dar significados ao que se faz, como favorece a provável construção de uma história das realizaçóes na terapia ocupacional. Lembramos aqui das colocaçôes de Mattingly (1998), de que o tempo clínico é um tempo narrativo e não cronológico.

Construçáo de Narrativa, enfim, quando, principalmente, fizermos uso da técnica trilhas associativas, que é o procedimento para a realização de uma análise de atividades partilhada com o sujeito alvo, construímos com o nosso sujeito alvo uma narrativa histórica de seu processo em terapia ocupacional.

Aqui temos descrito os temas que propomos aprofundar na formação clínica. Entretanto, não sendo esse nosso propósito aqui, queremos lembrar de como tudo isso começa, através da própria terapeuta ocupacional e da participação direta do sujeito alvo da terapia ocupacional. Lembramos novamente que nosso método é dinâmico e que o movimento dos três termos da relação é que define que caminho essa terapia vai trilhar.

\section{Proceder com atividades}

\subsection{No diagnóstico situacional}

Na prática direcionada pelo MTOD, primeiro precisamos conhecer o sujeito e seu cotidiano, nas suas atividades e relaçóes. Isto não pode ser feito apenas por meio de conhecer um diagnóstico médico ou conjunto de sintomas. É preciso saber quem esse sujeito é e o que faz, mesmo que sua única atividade ou participação seja a de estar há mais de um ano trancado no seu quarto, ou de não sair de casa na cadeira de rodas.

O diagnóstico situacional é uma descrição da situação do sujeito que se encontra conosco, e, nesse sentido, sendo por nós observado, levando-se em conta como ele se vê, como os outros o veem (indicando a qualidade de suas relaçóes no social), o que faz e como faz, mesmo que para nós fique claro, de início, que não gosta ou não quer fazer nada.

São as atividades do sujeito que darão as coordenadas para saber-se quem e como ele é.

\subsection{No decorrer da clínica}

A promoção das atividades como veículo de aquisiçóes de fora para dentro subsidia tanto a função terapêutica como a ação educativa. Aqui, estamos reforçando a ideia de que, na terapia ocupacional, os elementos do mundo externo (o que é de fora), representados fortemente pelas atividades, exercem influências no mundo interno, em direção a integraçoos e interaçóes (BENETTON, 2008).

Desse modo, no processo de realização de atividades e em seus desdobramentos - indicar caminhos, ensinar, educar, orientar, como atitudes positivas e ativas da terapeuta ocupacional - devem existir espaços para o fazer, para abandonos e novas escolhas, decisões sobre como fazer e o que fazer com os produtos das atividades, pensar e conversar sobre elas, dar-lhes significados momentâneos ou significando-as numa narrativa histórica, como acontece nas trilhas associativas. Como podemos ver, a terapeuta ocupacional pode manejar uma multiplicidade de acontecimentos para que o paciente possa nomear aquisiçóes, habilidades, construçóes e autoconhecimento, enriquecendo com isso sua vida cotidiana.

Dessa forma, o setting da terapia ocupacional, que sustenta a relação triádica, é promotor de atividades e encontra-se aberto para que o sujeito possa entrar e dele sair (BENETTON, 2006; FERRARI, 2008). Ele, e a própria terapia, devem ser constructos representativos do cotidiano (BENETTON, 2010) e, portanto, relevantes para a vida.

Vemos isso mesmo em quadros de terminalidade, pois, como aprendemos com Mastropietro, Santos e Oliveira (2008, p. 20), nessas situações os pacientes envolvem-se com atividades de vida na terapia ocupacional, e não com a morte.

O processo de terapia ocupacional passa a assumir diferentes significados, dependendo do momento de vida e da história pessoal de cada paciente. Aproximando-se da morte, podemos observar momentos intensos de vida. Enquanto há vida é com ela que lidamos.

\section{3 $\mathrm{Na}$ avaliação}

Em princípio, consideramos que avaliar um sujeito em terapia ocupacional é, antes de tudo, saber como é o seu cotidiano e qual é a repercussão social de suas realizaçóes, ou mesmo o que são consideradas realizaçôes ou ações sem sentido, ou as que apenas dão sentido à sua doença ou deficiência. 
Especificamente no nosso setting, utilizamos a técnica trilhas associativas. Durante o processo terapêutico, a terapeuta ocupacional vai construindo hipóteses formuladas através de observaçôes e coleta de informaçōes, sobre os motivos das açôes, atitudes, gestos e atividades do paciente, imerso na dinâmica de ação e reação proporcionada pela relaçâo triádica. Essas hipóteses associativas, guardadas na memória, acrescidas das atividades, que mostram produtos de diferentes qualidades, são os desencadeantes de histórias de uma relação de produção.

Inicialmente, a técnica trilhas associativas foi desenvolvida como um procedimento de análise de atividades, buscando-se "[...] colocar uma relação a salvo de enganos e determinaçóes, comuns no pré-julgamento [...]" (BENETTON, 2006, p. 114), pois o sentido é sempre dado pelo sujeito. Isto quer dizer que, ao contrário das análises de atividades preestabelecidas, no MTOD nos propomos a realizá-la com a participaçáa direta do sujeito alvo, em um processo posterior à realização das atividades, de tal forma que cada uma delas possa ser significada ou posta em uma narrativa histórica.

Falamos aqui de uma cadeia de significados, e náo de um significado para cada atividade ou fato de forma isolada uns dos outros, que não acontece em um tempo cronológico, sequencial, mas sim em um tempo narrativo, atemporal, causal (MATTINGLY, 1998). Isso também nos leva a entender que realizar atividades significativas se torna muito mais um resultado da maneira de como se está nessa relação do que do pré-estabelecimento de sentidos ou significados. Essa proposta possivelmente se diferencia de análises de atividades usualmente descritas na literatura internacional, sejam elas centradas na tarefa, na teoria ou mesmo no sujeito - para atender aos objetivos do cliente (CREPEAU, 2002), porque demanda a existência de um tempo narrativo em que o tempo e o espaço vividos comecem a fazer sentido (MARCOLINO, 2012).

Nessa direção, esse procedimento abre espaço para que novas histórias possam ser contadas, a partir de aspectos que não eram pensados ou associados, e assim um "novo sistema de valores vai sendo construído" (BENETTON, 2010, p. 106). Assim, o valor que um sujeito possa dar às atividades não estará atrelado antecipadamente à sua doença, sintomas ou deficiências, mas sim ao sentido que essas atividades tiveram na sua relação com a terapeuta ocupacional ou com o desenrolar das repercussóes da terapia em seu cotidiano, pois ao buscar aspectos saudáveis nas relaçóes, procuramos provocar o surgimento de significados e sentidos que ampliem produtivamente o cotidiano de nossos sujeitos alvos, de modo a ele poder, ou mesmo aprender, a investir em sua produção.

Acreditamos que através dessa significação, o sujeito alvo possa tomar em suas máos seu jeito de ser, estar, relacionar-se e fazer, impondo à sociedade que o receba desse jeito, sem que precise esperar pela mudança social para nela se inserir, e, desse modo, torna-se ele mesmo agente dessa mudança (BENETTON, 2010).

Essa é nossa ideia-guia para lidar com o tema avaliação em terapia ocupacional, bem como para ponderar o caminho que uma terapia segue, pois como nos diz Mattingly (1998), uma boa terapia é avaliada pelo conjunto de açóes públicas, mas também pelo conjunto invisível de emoçóes, sentimentos, julgamentos e percepçôes. A narrativa construída nas trilhas, contendo comparações, aceitações, rejeiçôes, associaçóes, significa, de começo, a relação triádica; a história dessa relação de construção no setting, positivamente sustentada.

As técnicas de ensino e aprendizagem de atividades, de análise, de desenvolvimento da relação triádica e as de avaliação são conceitualmente desenvolvidas de forma a permitir um proceder de cada terapeuta ocupacional em qualquer clínica ou área em que atue.

\subsection{Os recursos}

O MTOD está sendo construído dentro de uma lógica que nos permite caminhar por definiçôes, conceitos, técnicas e procedimentos próprios. Podemos ainda seguir rotas de outras disciplinas, cujas definiçóes e conceitos consideramos periféricos, e cujos procedimentos e técnicas seráo como recursos auxiliares para a realização de atividades.

Nesse caso, trata-se de utilizarmos um recurso para conseguirmos que o sujeito realize atividades.

Por definição, recurso é algo que pode melhorar ou facilitar uma situação difícil (HOUAISS, 2009). Assim sendo, um recurso pode vir de uma técnica ou um dispositivo que nos facilite, especificamente, a realização de atividades.

Diferente do instrumento atividades ${ }^{4}$, um recurso pode ser abandonado, mudado ou inutilizado numa relaçáo de terapia ocupacional (BENETTON, 2008). Um exemplo simples disso é usarmos um garfo adaptado para que um paciente com dificuldades de preensão possa comer sozinho. É assim também no uso de algum exercício físico ou de uma técnica de desenvolvimento de atenção, concentração e memória.

Recursos estão geralmente atrelados ao tratamento de déficits ou à adaptação para capacidades remanescentes. Entretanto, no MTOD, como 
dito anteriormente, os recursos são chamados diante da abertura para a realização de algum projeto de atividade, para se "[...] fazer algo que é desejado ou o que se precisa fazer [...]" (MARCOLINO, 2003, p. 57).

Nesse sentido, os recursos servirão para sempre na vida do sujeito ou poderão ser abandonados ao longo do seu tratamento.

É preciso lembrar que uma pessoa nunca é um recurso, isto é, se um paciente tiver que ser atendido por uma outra terapeuta ocupacional ou estiver sempre sendo acompanhado por um cuidador, essas pessoas nunca serão consideradas como recursos, mas assim poderão ser relaçôes com proposiçôes de novas associaçóes, interaçóes e integraçôes.

Quando atendemos junto com alguma colega, quando uma família é atendida, quando atendemos em grupo ou em situaçôes de setting estendido - nas escolas, hospitais ou sociedade - consideramos esses elementos participantes, como o quarto termo de uma relação originariamente triádica. Nesse caso, uma nova dinâmica é sempre instituída e cabe à terapeuta ocupacional sempre abarcá-la em benefício do sujeito alvo, do seu tratamento e educação.

\section{Considerações finais}

Ao buscarmos falar das atividades no MTOD, procuramos abordar a forma como estruturamos o pensamento sobre elas. Essa estrutura pode parecer complexa ou, para quem olhe sem o devido aprofundamento, desnecessária, mas ela reflete, na verdade, a importância dada ao estudo do uso das atividades, quando em terapia ocupacional, dos fenômenos que podem ser aí observados. Para essas elaborações, a terapia ocupacional, enquanto prática de cuidado centrada na singularidade dos casos, foi posta como objeto de estudo, na tentativa de percorrer um caminho de construção de conhecimento que permita generalizaçôes - caminho percorrido por Benetton nos últimos 30 anos. O esquema conceitual e instrumental apresentado neste trabalho decorreu desse esforço.

Dessa forma, estruturamos este texto de modo a caminhar inicialmente pelos aspectos gerais das atividades no MTOD, como a opção pelo nome "atividades", sua definiçấo conceitual, sua utilização como instrumento e sua participação ativa na dinâmica da relação triádica. Na sequência, falamos do caráter das atividades - terapêutico, educativo e social, qualidades peculiares que demarcam essa terapia ocupacional.
Depois disto pudemos entấo falar do uso das atividades como instrumento, tanto como elemento central nos processos que devem sustentar o raciocínio clínico (observação, informação, associação, estabelecimento de espaço de historicidade e construçáo de narrativa), como nos procedimentos de diagnóstico, no decorrer da clínica e na avaliação do processo.

Por fim, pudemos falar de nossa compreensão do que são recursos no MTOD e de sua ligação intrínseca com a possibilidade de se realizarem atividades.

Neste texto, optamos por uma abordagem teórica e deixamos os exemplos clínicos para os artigos publicados, em sua maioria, no periódico clínico Revista CETO e também, atualmente, em algumas dissertaçóes e teses acadêmicas que buscam sistematizar e validar o conhecimento que temos produzido no CETO para a assistência em terapia ocupacional.

Esperamos que esta apresentação possa ser útil para a formação inicial e continuada em Terapia Ocupacional, bem como para enriquecer o debate sobre o uso de atividades na profissão.

\section{Referências}

BENETTON, M. J. A terapia ocupacional como instrumento nas açôes de saúde mental. 1994. 190 f. Tese (Doutorado em Saúde Mental)-Faculdade de Ciências Médicas, Universidade de Campinas, Campinas, 1994

BENETTON, M. J. História comparada da Terapia Ocupacional Brasil-França. São Paulo: FAPESP, 1998. Relatório de pesquisa.

BENETTON, M. J. Além da opinião: uma questão de investigação para a historicização da Terapia Ocupacional. Revista CETO, São Paulo, v. 9, n. 9, p. 04-08, 2005.

BENETTON, M. J. Trilhas Associativas: ampliando subsídios metodológicos à clínica da terapia ocupacional. Campinas: Arte Brasil Editora, UNISALESIANO, Centro Universitário Católico Auxilium, 2006.

BENETTON, M. J. Atividades: tudo o que você quis saber e ninguém respondeu. Revista CETO, São Paulo, v. 11, n. 11, p. 26-29, 2008.

BENETTON, M. J. O encontro do sentido do cotidiano na Terapia ocupacional para a construção de significados. Revista CETO, São Paulo, v. 12, n. 12, p. 32-39, 2010.

BENETTON, J.; TEDESCO, S.; FERRARI, S. Hábitos, cotidiano e Terapia Ocupacional. Revista CETO, São Paulo, v. 8, n. 8, p. 27-40, 2003.

CREPEAU, E. B. Análise de atividades: uma forma de refletir sobre desempenho ocupacional. In: NEISTADT, M. E.; CREPEAU, E. B. (Orgs). Willard \& Spackman Terapia Ocupacional. Rio de Janeiro: Guanabara Koogan, 2002. p. 121-133. 
CUNHA, A. G. Dicionário etmológico. Rio de Janeiro: Nova Fronteira, 1986.

FERRARI, S. M. L. Análise de atividades. Revista CETO, São Paulo, v. 11, n. 11, p. 36-40, 2008.

HOUAISS, A. Dicionário Houaiss da Lingua Portuguesa. São Paulo: Objetiva, 2009.

KIELHOFNER, G.; BURKE, J. Occupational therapy after 60 years: an account of changing identity and knowledge. American Journal of Occupational Therapy, New York, v. 31, p. 675-689, 1977.

KUHN, T. A estrutura das revoluçôes cientificas. São Paulo: Editora Perspectiva, 2003.

LE PETIT ROBERT Dictionaires Le Robert. Paris: Le Robert, 1993.

LATOUR, B. A esperança de Pandora. Bauru: EdUSC, 2001.

LIMA, E. M. F. A.; PASTORE, M. N.; OKUMA, D. G. As atividades no campo da Terapia Ocupacional: mapeamento da produção científica dos terapeutas ocupacionais brasileiros de 1990 a 2008. Revista de Terapia Ocupacional da USP, São Paulo, v. 22, n. 1, p. 68-75, jan./abr. 2011.

MARCOLINO, T. Q. Sobre reabilitar o que não se reabilita. Revista CETO, São Paulo, v. 8, n. 8, p. 54-58, 2003.

MARCOLINO, T. Q. O raciocínio clínico da terapeuta ocupacional ativa. Revista CETO, São Paulo, v. 13, n. 13, p. 14-25, 2012.
MARCOLINO, T. Q.; FANTINATTI, E. N. As transformaçóes no uso e no conceito de atividades na obra de Jô Benetton. In: CONGRESSO BRASILEIRO DE TERAPIA OCUPACIONAL, 13., 2013, Florianópolis. Anais... Florianópolis: Associação Brasileira dos Terapeutas Ocupacionais Regional de Santa Catarina, 2013.

MASTROPIETRO, A. P.; SANTOS, M. A.; OLIVEIRA, E. A. A clínica da terminalidade. Revista CETO, São Paulo, v. 11, n. 11, p. 18-25, 2008.

MATTINGLY, C. Healing dramas and clinical plots: the narrative structure of experience. Cambridge: Cambridge University Press, 1998.

MORAES, G. C. Atividades: uma compreensão dentro da relação triádica. Revista CETO, São Paulo, v. 11, n. 11, p. 30-35, 2008.

NICOLELIS, M. Muito Além Do Nosso Eu. São Paulo: Companhia das Letras, 2011.

SLAGLE, E. C. Treinando ajudantes para pacientes com deficiência mental. Tradução: Joana Benetton. Revista CETO, São Paulo, v. 8, n. 8, p. 8-12, 2003.

WAGNER, R. A invenção da cultura. Tradução: Marcela Coelho de souza e Alexandre Morales. São Paulo: Cosac Naify, 2010.

WORLD FEDERATION OF OCCUPATIONAL THERAPISTS. Definition of Occupational Therapy. 2012. Disponível em: <http://www. wfot.org/AboutUs/AboutOccupationalTherapy/ DefinitionofOccupationalTherapy.aspx>. Acesso em: 05 maio 2013.

\section{Contribuição dos Autores}

Ambas as autoras participaram da concepçáo, do desenvolvimento e da redação do texto.

\section{Notas}

${ }^{1}$ O CETO, hoje Centro de Especialidades em Terapia Ocupacional, desde o final da década de 1970 dedica-se ao estudo, pesquisa e clínica em Terapia Ocupacional, sendo, atualmente, o centro para a formação clínica/especialização no Método Terapia Ocupacional Dinâmica. É coordenado por Jô Benetton e Sonia Ferrari, localiza-se em São Paulo, capital, embora a formação clínica ocorra em turmas por todo o território nacional.

${ }^{2}$ Terapia Ocupacional com as iniciais em letra maiúscula se refere à profissão, e terapia ocupacional com iniciais em letra minúscula se refere à prática clínica-assistencial, conforme notação sugerida por Benetton (1994).

${ }^{3} \mathrm{O}$ termo terapeuta ocupacional virá acompanhado de artigo feminino, a terapeuta ocupacional, dada a maioria de mulheres profissionais.

${ }^{4}$ As atividades, como instrumento, não podem ser abandonadas, pois são o terceiro termo da relação triádica. É com elas que a terapeuta ocupacional trabalha, no sentido geral do termo. Aqui, estamos organizando o pensamento de forma teórica e conceitual. Entretanto, atividades como produtos ou mesmo projetos de atividades podem ser abandonadas pelos pacientes, pois estamos trabalhando com o reconhecimento do desejo e, muitas vezes, com o surgimento dele, como ressalta Moraes (2008). 